\title{
The Effect of Mobile Application Support for Postpartum Women on Postpartum Quality of Life
}

\author{
Pınar Mallı ${ }^{1}$ (), Ayla Ergin ${ }^{2}$ \\ ${ }^{1}$ Geb-be, Pregnancy, Birth and Postpartum Counseling Company, Tuzla, Istanbul, Turkey. \\ ${ }^{2}$ Kocaeli University, Associate Professor, Faculty of Health Siences, Midwifery Department, Kocaeli, Turkey. \\ Correspondence Author: Ayla Ergin \\ E-mail: ayla.ergn@gmail.com \\ Received: 03.05.2020 Accepted: 18.04.2021
}

\begin{abstract}
Objective: This study aims to determine the effect of a mobile application prepared by midwives on postpartum quality of life, and to present a mobile training method for use by health care professionals.

Methods: The sample for this randomized controlled study consisted of 64 (experimental group $=32$, control group $=32$ ) postpartum women for whom inclusion criteria for participation in the study were that they presented to a private counseling center had the ability to use the internet and mobile applications. The study was conducted between March 1, 2018 and July 15, 2019. Data were collected using the Maternal Postpartum Quality of Life Questionnaire (MAPPQOL) and the Web-based Education Software Scale (WBESS) to gather descriptive characteristics of the participants and obstetric data. Applicable statistical methods, which included Mann-Whitney U test, and Spearman correlation test.

Results: The mean scores on the MAPPQOL for the control and experimental group were $21.99 \pm 2.97$ and $20.30 \pm 4.33$. There was nostatistically significant difference between the mean scores obtained by the two groups on the MAPPQOL $(p=0.073 ; p>0.05)$. Furthermore, there was no statistically significant relationship between the mean scores on the total MAPPQOL and the mean MAPPQOL subscale scores of the experimental group and the mean scores on the WBESS and the subscale scores of this scale ( $p>0.05)$. It was found that the experimental group's competence level of the mobile application $(62.5 \%, \mathrm{n}=32)$ was very good according to their WBESS mean score.

Conclusion: Postpartum quality of life score swere found to be higher in the postpartum patients who used the mobile application and it was observed that mobile application support increased postpartum quality of life. The scope was found to be valid this comprehensive mobile training model can be in recommended for use midwifery applications.
\end{abstract}

Keywords: Midwifery, mobile application, mobile health, postpartum, postpartum quality of life, innovation in midwifery

\section{INTRODUCTION}

The postpartum period is considered to be a period of critical importance for the mother, baby and family $(1,2,3)$. In recent years, guidelines have been updated and technological developments have been used to reduce maternal / neonatal mortality and morbidity rates during this critical period $(4,5)$.

Mobile technologies are recognized as being one of the fastest-adopted technologies in human history and they have had a strong impact on society as a whole by providing costeffective communication (6). The use of technology is seen as a promising innovation that can revolutionize the public's access to health care, the provision of quality health care and cost-effectiveness (7).

Mobile health (mHealth) is defined as "health services provided through mobile communication devices". The WHO defines it as "complementary and innovative health practices, executed through the widespread mobile communications technology and in frastructure, with beneficial contributions that serve to improve the effectiveness and function of the current health system via its numerous capacities, such as health promotion, remote disease management, health data collection and early warning system" $(8,9)$.

The mobile health applications prepared by midwives have been shown to increase efficiency and effectiveness of care, to provide motivation and to serve as an important information source. They support clinical decision making, alleviate administrative burdens and increase the speed of data collection to be used for evaluation (10). The applications also enable midwives to reach the mother in time and to provide them with consistent, evidence-based information $(11,12)$.

Every parent has unique learning needs, depending on the situation, so the training materials provided must be personalized. Moreover, early discharge after birth may not give postpartum women the opportunity to acquire 
booklets or brochures regarding the care of newborn babies (13). For this reason, the use of downloadable applications for postpartum women and their spouses that feature information on the postpartum period and newborn care, breastfeeding training, general information, videos, visuals and one-to-one consultation with midwives may help them to beter adapt to their roles as mother and father, increase their quality of life, develop their self-care skills, increase their health levels and give them confidence on account of the constant reassurance that their midwives are with them. Shorey (2018) reported that their mobile application "at home but not alone" gave the parents the feeling of being part of a virtual community outside the hospital, the feeling of not being alone in this process and being helped by a midwife through out the postpartum period, which simultaneously made them feel safe (7).

In summary, in the postpartum period, which is considered a stressful and critical transition period, mothers can be provided with postpartum support by midwives through mobile applications, whereby their quality of life will be improved by ensuring they undergo a positive and healthy experience during this challenging period. To date, there have been no experimental mobile application studies specific to the postpartum period that have been conducted in any country worldwide, including Turkey. Therefore, being the first of its kind, this study is important for the literature, as it aims to determine the effect of a mobile application, prepared by midwives and used in the postpartum period, on the quality of life in the postpartum period and to provide a mobile training method for health professionals.

\section{METHODS}

\subsection{Design and Sample}

The study was designed as a randomized controlled study and was carried out at a private pregnancy, childbirth and postpartum counseling clinic in the province of Istanbul in Turkey from 01.05.2019 to 15.06.2019 with 64 postpartum women. The inclusion criteria for participation in the study were that the women be postpartum, between the ages of 18 and 40 years, experiencing their first, spontaneous single delivery, have no communication difficulties, no chronic diseases, no psychiatric diseases and no obstetric risks (diabetes, pre-eclampsia, PEM etc.), and be able to read and use the internet and mobile applications. The study flow diagram is presented in Figure 1.

Ethics committee approval, numbered KU-GOKAEK 2018/121 and dated 21.03.2018, was received prior to the study. Randomizations were performed at https://www.random. org on 11.01.2019. Numbers, like 61, 15, 52, 22.... are included into the experimental group.

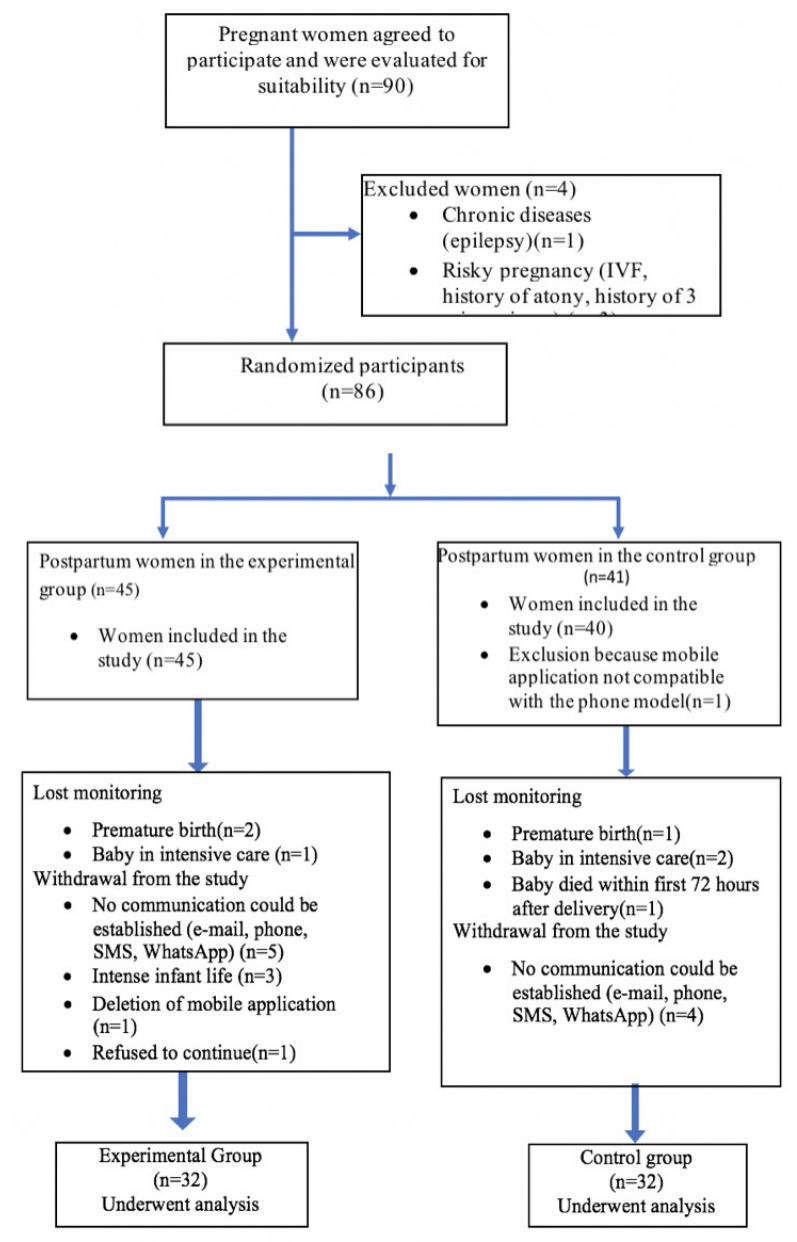

Figure 1: The study flow diagram

\subsection{Instruments}

The study data were obtained through a questionnaire consisting of 41 question sprepared by the researchers in accordance with the literature, an information booklet containing educational content to be included in the mobile application, theTraining Material Evaluation Form, a webbased education software scale and the Maternal Postpartum Quality of Life Questionnaire.

A web-based education software scale developed by Fiş Erümit in 2011, 23 items collected under four factors, and is used to evaluate Web Based Training materials. The items in the scale are structured as "strongly agree", " agree", " indecisive", " disagree" and " strongly disagree". Cronbach Alpha value of the scale was found to be 0.915 and its reliability was found to be acceptable (15).

The training material prepared by there searchers and the" Training Material Evaluation Form", prepared by Top in 2012, were sent to 12 experts and edited in line with their expert recommendations (16). The experts results were evaluated with the Kendall's coefficient of concordance test, from which a significant relationship was found $(W=0.413, \chi 2=63.565$ and $S D=11, p$ 0.001), indicating that the experts' opinions were compatible with one another. The validity scale for the 
scope of the training material, which was developed by Hill et al. (2006) and whose study on validity and reliability for use in Turkey was conducted by Altuntuğ and Ege (2012), was used in this study $(17,18)$. The scale includes 40 items, arranged under 5 subdimensions, and is applied to determine postpartum quality of life according to the perception of the mother. The Cronbach's alpha value was determined to be $0.95(18)$. Prior to the study, permission to use the scale was granted by the original authors for the evaluation of the postpartum quality of life of the participating women. The educational content related to the health of the mother, baby and father was transferred to the mobile application.

In addition, to determine whether the questionnaire was comprehensible or not, 10 postpartum women under went a pre-application. The data derived from this pre-application, however, was not included in the study.

\subsection{Data Collection}

The mobile application was developed with the support of a software development company. The most important features of this mobile applicationarethat it is user-friendly, easy to understand, providing information content with training videos and providing one-to-one online message support to puerperant women and using it for IOS and Android operating systems. The researchers prepared the educational material, visuals and videos and questionnaires, scales and visuals were added to the mobile application, which was started after user and developer software tests were carried out (Figure 2). Users in experimental group supported with three catagories which are mother - father and newborn. For Mother: postpartum changes, mental changes, self-care of mother, breastfeeding, sexual health, reproductive health, postpartum exercise, maternal nutrician, emergency case, mother-baby attachment etc. For Father: role adaptation, participation to baby care, comminication with partner and sexual health etc. Newborn: newborn physiological characteristics, newborn care, breasfeeding, vaccine, common problems, baby development, emergency cases etc. The contents are enriched with videos that facilitate the application. For example; bath, diaper changes, breastfeeding and other problems etc. Online midwife support for questions of experimental groups.

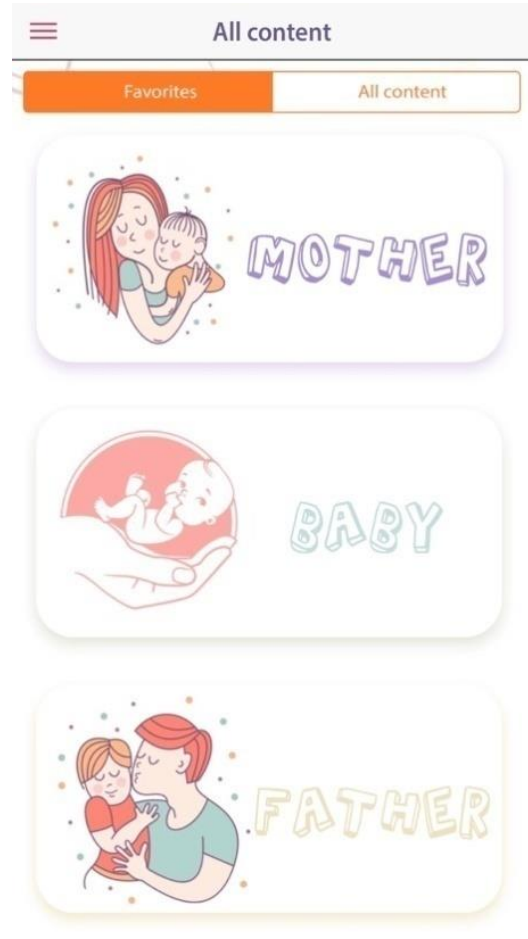

\begin{tabular}{l} 
All content \\
\hline+ All content \\
\hline+ Physical changes \\
\hline+ Mental changes \\
\hline+ Self-care of the mother \\
\hline+ Breastfeeding \\
\hline Exercises
\end{tabular}

Figure 2. Mobile application image (prepared by Pınar Mallı)

\section{Application steps for the experimental group:}

1. Get acquainted with the pregnant women after the 30th week of pregnancy via phoneor video call; explainthecontent of the study; request information from the participating pregnant women on their mailing address, phone number and expected delivery date; and record this information,
2. Enter the contact information of the pregnant women who were selected to be part of the experimental group by randomization on to the mobile application admin panel; and send an information form and download link on how touse the mobile application,

3. Downloading of the application before delivery date, 
4.Create the username and password for the pregnant women on the day of birth; distribute electronically informed consent; and login to the mobile application and choose the type of birth,

5. Submit a photo of the bracelet worn in the hospital to the study supervisor to preventf alse login; and login to the user account from the mobile application admin panel through the authentication process performed with the submitted photo,

6. Re-login of the user on to the mobile application,

7. Fill out the socio-demographic questionnaire,

8. Read and watch the educational material and contact the mobile application manager for consultation purposes via the "ask your midwife" tab, located under each subject content,

9. Fill out the Quality of Life scale six weeks after givin gbirth,

10. With the completion of the web-based education software scale, the study is concluded.

The postpartum women in the experimental group were provided with educational content via a mobile application for six weeks.

The control group was asked to login to the mobile application and fill out the questionnaire and postpartum quality of life scales. All materials that were prepared for the experimental groupwere sent to the control group via e-mail to ensure similar information.

After this process, the entries of the experimental and control groups were completed between 01.05.2019 and 24.07.2019 and later. The study was produced from a project, access to the software was granted till a month after the project ended. (Last access date: 1.09.2020)

\subsection{Ethical Considerations}

The study was approved by the Ethics Committee (Approval Date: KU-GOKAEK 2018/121) and conducted according to the ethics guidelines established in the Declaration of Helsinki. Written consent was obtained from patients who agreed to enroll in the study. All participants were informed about the purpose and design of the study.

\subsection{Statistical Analysis}

For statistical analysis, NCSS (Number Cruncher System) 2007 (Kaysville, Utah, USA) software was used. During evaluation of the data, descriptive statistical methods such as mean, standard deviation, median, frequency and percentage. Regular distribution of quantitate data was tested by SapiroWilk test and analysis of the graphical outputs. Comparative analysis of the quantitative data displaying normal distribution between two groups was performed with Student t test, while quantitative data that did not display test. Comparative analysis of the quantitative data displaying normal distribution was evaluated with Mann-Whitney $U$

normal distribution among the three or more groups was performed with OnewayAnova test and for dual comparisons Benforroni test was used. Comparative analysis of the quantitative data that did not display normal distribution among the three or more groups was performed with Kruskal Wallis test and dual comparisons Benforroni test was used. For comparison of qualitative data Chi-square test, Fisher's Exact test and Fisher-Freeman-Halton test were used. To evaluate the correlations among the qualitative variants, Pearson Correlation and Spearman's correlation analyses were used. For evaluation of the validity of education materials, Kendall correlation analysis was performed. $\mathrm{P}<0.05$ was accepted to be statistically meaningful.

\section{RESULTS}

The meanage of the participants was $29.72 \pm 3.74$, with a ranged of 20 to 38 years, and the mean duration of marriage was $3.03 \pm 1.99$ years, with a range of 1 to 9 years. Other descriptive characteristics are given in Table 1.

Table 1. Socio-demographic characteristics of the participants

\begin{tabular}{|c|c|c|c|}
\hline & $\begin{array}{l}\text { Experimental } \\
\text { group }(n=32)\end{array}$ & $\begin{array}{c}\text { Control } \\
\text { group }(n=32)\end{array}$ & \multirow[t]{2}{*}{$P$ Value } \\
\hline & $n(\%)$ & $n(\%)$ & \\
\hline \multicolumn{3}{|l|}{ Age (years) } & \multirow{3}{*}{${ }^{\mathrm{a}} 0.289$} \\
\hline Min-Max (median) & $22-38(30.5)$ & $20-36(29)$ & \\
\hline Mean+SD & $30.22 \pm 3.80$ & $29.22 \pm 3.68$ & \\
\hline \multicolumn{3}{|l|}{ Marriage duration (years) } & \multirow{3}{*}{${ }^{\mathrm{b}} 0.133$} \\
\hline Min-Max (median) & $1-9(3)$ & $1-9(2)$ & \\
\hline Mean+SD & $3.34 \pm 2.04$ & $2.72 \pm 1.92$ & \\
\hline \multicolumn{3}{|l|}{ Educational Status } & \multirow{3}{*}{${ }^{\mathrm{c}} 0.672$} \\
\hline High School & $4(12.5)$ & $2(6.3)$ & \\
\hline University & $28(87.5)$ & $30(93.8)$ & \\
\hline \multicolumn{3}{|l|}{ Occupation } & \multirow{5}{*}{${ }^{\mathrm{d}} 0.040^{*}$} \\
\hline Housewife & $7(21.9)$ & $4(12.5)$ & \\
\hline Worker-Freelancer & $5(15.6)$ & $1(3.1)$ & \\
\hline Civil servant & $4(12.5)$ & $13(40.6)$ & \\
\hline Other & $16(50.0)$ & $14(43.8)$ & \\
\hline \multicolumn{3}{|l|}{ Economic Status } & \multirow{3}{*}{${ }^{\mathrm{e}} 0.226$} \\
\hline $\begin{array}{l}\text { Income is less/equal to } \\
\text { expenses }\end{array}$ & $23(71.9)$ & $27(84.4)$ & \\
\hline $\begin{array}{l}\text { Income is more than } \\
\text { expenses }\end{array}$ & $9(28.1)$ & $5(15.6)$ & \\
\hline \multicolumn{3}{|l|}{ Family type } & \multirow{3}{*}{${ }^{\mathrm{c}} 0.492$} \\
\hline Nuclear family & $32(100)$ & 30 (93.8) & \\
\hline Extended family & $0(0)$ & $2(6.3)$ & \\
\hline $\begin{array}{l}\text { aStudent } t \text { Test } \quad{ }^{b} \text { Mann Wh } \\
{ }^{d} \text { Fisher Freeman Halton Test } \\
{ }^{*} p<0.05\end{array}$ & itney U Test & $\begin{array}{r}\text { 'Fisher's } \\
{ }^{e} \text { Pearson Chi-S }\end{array}$ & $\begin{array}{l}\text { Exact Test } \\
\text { yuare Test }\end{array}$ \\
\hline
\end{tabular}


Among the participants, $90.6 \%(n=58)$ stated that their pregnancy was planned and $95.3 \%(n=61)$ said that they wanted this pregnancy. In addition, $50 \%(n=32)$ had a normal birth and $50 \%(n=32)$, a cesarean section (Table 2). When examining the newborn characteristics, it was observed that their gestation weeks varied from 37 to 42 weeks, with the mean being $38.91 \pm 1.18$ weeks.

Table 2.Comparison of obstetric characteristics of participants

\begin{tabular}{|c|c|c|c|}
\hline & $\begin{array}{l}\text { Experimental } \\
\text { group }(n=32)\end{array}$ & $\begin{array}{c}\text { Control } \\
\text { group }(n=32)\end{array}$ & \multirow[t]{2}{*}{$\begin{array}{c}P \\
\text { Value }\end{array}$} \\
\hline & $n(\%)$ & $n(\%)$ & \\
\hline \multicolumn{3}{|c|}{ Planned pregnancy } & \multirow{3}{*}{${ }^{\mathrm{c}} 0.196$} \\
\hline Yes & $27(84.4)$ & 31 (96.9) & \\
\hline No & $5(15.6)$ & $1(3.1)$ & \\
\hline \multicolumn{3}{|l|}{ Wanted pregnancy } & \multirow{3}{*}{${ }^{c} 1.000$} \\
\hline Yes & 31 (96.9) & $30(93.8)$ & \\
\hline No & $1(3.1)$ & $2(6.2)$ & \\
\hline \multicolumn{3}{|c|}{ Latest type of birth } & \multirow{3}{*}{${ }^{\mathrm{e}} 1.000$} \\
\hline Normal birth & $16(50.0)$ & $16(50.0)$ & \\
\hline Cesarean section & $16(50.0)$ & $16(50.0)$ & \\
\hline \multicolumn{3}{|c|}{ Satisfied with the type of birth } & \multirow{3}{*}{${ }^{c} 0.098$} \\
\hline Yes & $29(90.6)$ & $24(75.0)$ & \\
\hline No & $3(9.4)$ & $8(25.0)$ & \\
\hline \multicolumn{3}{|c|}{$\begin{array}{l}\text { Sufficient help from the spouse } \\
\text { during pregnancy and birth }\end{array}$} & \multirow{3}{*}{${ }^{\mathrm{e}} 0.098$} \\
\hline Yes & $29(90.6)$ & $24(75.0)$ & \\
\hline Partial/No & $3(9.4)$ & $8(25.0)$ & \\
\hline
\end{tabular}

${ }^{\mathrm{c} F i s h e r ' s ~ E x a c t}$ Test, ${ }^{\mathrm{d}}$ Fisher Freeman Halton Test, ${ }^{\mathrm{e}}$ Pearson Chi-Square Test

The participants' internet usage durations varied between 3 and 23 years and had a mean value of $12.97 \pm 4.14$ years. There was no significant difference between the groups in terms of internet usage duration, time spent online, purpose of internet use and web pages found to have reliable information ( $p>0.05$ ) (Table 3).

The Cronbach's alpha coefficients of the MAPPQOL subdimensions were $0.848,0.811,0.694,0.843$ and 0.876 , respectively. The total Cronbach's alpha coefficient of the MAPPQOL scale was 0.944 and the scale was foundto be highly reliable (Table 4).

In examining the MAPPQOL sub dimensions, the "kinshipfamily-friend/relationship" score varied from 4.3 to 26.2, with a mean of $18.38 \pm 4.44$, the "socio-economic" score varied from 12.8 to 29.4 , with a mean of $23.63 \pm 3.66$, "spouse/ relationship"score varied from 8.4 to 30 , with a mean of $24.47 \pm 4.21$, the "health/functionality" score varied from 1.5 to 28.8 , with a mean of $19.57 \pm 5.18$, the "psychological/baby" score varied from 6.8 to 29.7 , with a mean of $21.31 \pm 5.00$ and the total score varied from 6.7 to 27.9 , with a mean of $21.15 \pm 3.78$.

Table 3.Comparison of the results of regarding internet use

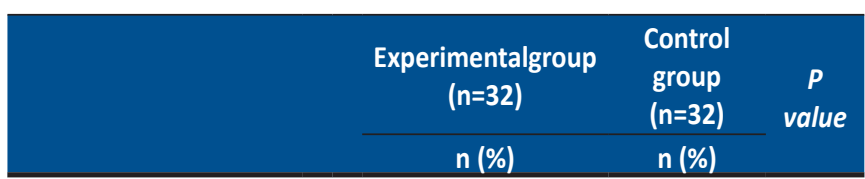

Duration of internet

use (years)

\begin{tabular}{|c|c|c|c|}
\hline & \multirow{3}{*}{${ }^{\mathrm{b}} 0.924$} \\
\hline Min-Max (median) & $5-20(14)$ & $3-23(13)$ & \\
\hline Mean+SD & $13.06 \pm 4.06$ & $12.88 \pm 4.28$ & \\
\hline \multicolumn{3}{|l|}{ Time spent online } & \multirow{5}{*}{${ }^{\mathrm{d}} 0.435$} \\
\hline 1 hour a day & $2(6.3)$ & $4(12.5)$ & \\
\hline 2 hours a day & $11(34.4)$ & $6(18.8)$ & \\
\hline 3 hours a day & $10(31.3)$ & $14(43.8)$ & \\
\hline 4 hours a dayormore & $9(28.1)$ & $8(25)$ & \\
\hline \multicolumn{4}{|l|}{ Purpose of internet use } \\
\hline Communication & $28(87.5)$ & $32(100)$ & ${ }^{\circ} 0.113$ \\
\hline Knowledge acquisition & $30(93.8)$ & $32(100)$ & ${ }^{\prime} 0.492$ \\
\hline $\begin{array}{l}\text { Confirming the reliability of } \\
\text { information }\end{array}$ & $17(53.1)$ & $21(65.6)$ & ${ }^{\mathrm{e}} 0.309$ \\
\hline Scientific studies/ Work & $19(59.4)$ & $20(62.5)$ & ${ }^{\mathrm{e}} 0.798$ \\
\hline Other & $8(25.0)$ & $9(28.1)$ & ${ }^{\mathrm{e}} 0.777$ \\
\hline
\end{tabular}

Web pages found to have reliable information

\begin{tabular}{lccc} 
Sites of official institutions & $28(87.5)$ & $27(84.4)$ & ${ }^{\mathrm{c}} \mathbf{1 . 0 0 0}$ \\
Sites of experts & $31(96.9)$ & $30(93.8)$ & ${ }^{\mathrm{c}} \mathbf{1 . 0 0 0}$ \\
Blogs & $12(37.5)$ & $8(25.0)$ & ${ }^{\mathrm{e}} \mathbf{0 . 2 8 1}$ \\
Other & $2(6.3)$ & $1(3.1)$ & ${ }^{\mathrm{c}} \mathbf{1 . 0 0 0}$ \\
\hline
\end{tabular}

-More than one answer was given. ' Mann Whitney U Test ' Fisher's

Exact Test ${ }^{\mathrm{d}}$ Fisher Freeman Halton Test, ${ }^{\mathrm{e}}$ Pearson Chi-Square Test

Table 4. Distribution of postpartum quality of life scale scores

\begin{tabular}{|c|c|c|c|c|c|}
\hline & $\begin{array}{l}\text { Number } \\
\text { of } \\
\text { questions }\end{array}$ & $\begin{array}{c}\text { Score } \\
\text { range } \\
\text { on the } \\
\text { scale }\end{array}$ & $\begin{array}{l}\text { Min-Max } \\
\text { (median) }\end{array}$ & $\begin{array}{l}\text { Mean } \\
(S D)^{a}\end{array}$ & $\begin{array}{c}\text { Cronbach's } \\
\text { alpha }\end{array}$ \\
\hline $\begin{array}{l}\text { Kinship- } \\
\text { Family-Friend } \\
\text { /relationship }\end{array}$ & 10 & $0-30$ & $\begin{array}{l}4.3-26.2 \\
(19.5)\end{array}$ & $18.38(4.44)$ & 0.848 \\
\hline $\begin{array}{l}\text { Socio- } \\
\text { economic }\end{array}$ & 9 & $0-30$ & $\begin{array}{l}12.8-29.4 \\
(24.1)\end{array}$ & $23.63(3.66)$ & 0.811 \\
\hline $\begin{array}{l}\text { Relationship } \\
\text { with spouse }\end{array}$ & 5 & $0-30$ & $\begin{array}{l}8.4-30 \\
(25.2)\end{array}$ & $24.47(4.21)$ & 0.694 \\
\hline $\begin{array}{l}\text { Health/ } \\
\text { functionality }\end{array}$ & 8 & $0-30$ & $\begin{array}{l}1.5-28.8 \\
(20.3)\end{array}$ & $19.57(5.18)$ & 0.843 \\
\hline $\begin{array}{l}\text { Psychological/ } \\
\text { baby }\end{array}$ & 8 & $0-30$ & $\begin{array}{l}6.8-29.7 \\
(22.5)\end{array}$ & $21.31(5.00)$ & 0.876 \\
\hline Total & 40 & $0-30$ & $\begin{array}{l}6.7-27.9 \\
(21.8)\end{array}$ & $21.15(3.78)$ & 0.944 \\
\hline
\end{tabular}

${ }^{a} 6$ point Likert scale with anchors of $1=$ very dissatisfied and $6=$ very satisfied 
In Table 5, the MAPPQOL scores of the participants were compared in terms of groups. No statistical significance could be found in terms of the relationship between kinshipfamily-friend/relationship, socio-economic and psychological/ babyscores ( $p>0.05)$. However, the spouse/relationship scores were statistically significant $(p=0.044 ; p<0.05)$ and the scores obtained by the experimental group were found to be higher.

Table 5. Distribution of web-based education software scale scores

\begin{tabular}{lccccc} 
& $\begin{array}{c}\text { Number } \\
\text { of } \\
\text { questions }\end{array}$ & $\begin{array}{c}\text { Score } \\
\text { range } \\
\text { on the } \\
\text { scale }\end{array}$ & $\begin{array}{c}\text { Min-Max } \\
\text { (median) }\end{array}$ & $\begin{array}{c}\text { Mean } \\
\text { (SD) }{ }^{\text {a }}\end{array}$ & $\begin{array}{c}\text { Cronbach's } \\
\text { alpha }\end{array}$ \\
\hline $\begin{array}{l}\text { Educational } \\
\text { compliance }\end{array}$ & 8 & $1-5$ & $2.9-5(4.5)$ & $4.38(0.60)$ & 0.917 \\
$\begin{array}{l}\text { Compliance } \\
\text { with the } \\
\text { training } \\
\text { program }\end{array}$ & 4 & $1-5$ & $2.8-5(4.5)$ & $4.34(0.61)$ & 0.875 \\
$\begin{array}{l}\text { Visual } \\
\text { sufficiency }\end{array}$ & 5 & $1-5$ & $2.8-5(4.4)$ & $4.36(0.60)$ & 0.868 \\
\hline $\begin{array}{l}\text { Programming } \\
\text { compatibility }\end{array}$ & 6 & $1-5$ & $2.5-5(4.5)$ & $4.33(0.68)$ & 0.925 \\
\hline \begin{tabular}{l} 
Total \\
\hline
\end{tabular} & 23 & $1-5$ & $2.9-5(4.4)$ & $4.35(0.58)$ & 0.970 \\
\hline
\end{tabular}

a 5 point Likert scale with anchors of $1=$ strongly agree and $6=$ strongly disagree

A statistically significant difference was found between the groups in terms of health/functionality $(p=0.044 ; p<0.05)$, with the scores of the experimental group being higher (Table 5). While there was no statistical difference between the two groups in terms of the MAPPQOL total score $(p=0.073 ; p>0.05)$, the scores of the experimental group were nonetheless higher than those of the control group.

The Cronbach's alpha coefficients of the WBESS subdimensions were $0.917,0.875,0.868$ and 0.925 , respectively. The total WBESS Cronbach's alpha coefficient was found to be 0.970 and the scale was found to be highly reliable (Table 5). No significant relationships between the MAPPQOL total score and subdimension scores and the WBESS total score and subdimension scores were determined between the groups $(p>0.05)$.

\section{DISCUSSION}

In this study, which aimed to determine the effect of a mobile application prepared by midwives on the quality of life during the postpartum period and to present a mobile training method for health workers, it was found that the participants in the experimental group had, on average, been internet users for 13.06 years, while those in the control group had been users for an average of $12.88 \pm 4.28$ years (Table 3 ). In a study, involving pregnant and postpartum women that was carried out in Turkey in 2016, 56.7\% of the women were reported to be internet users (19). Furthermore, a study carried out in America in 2015 with 100 pregnant women of different ethnicities reported that the internet usage rate was 94\% (20). The Internet andTechnology PEW Research Center
(2019) determined that the internet usage rate of adults in America in the year 2000, when it began to systematically monitor internet usage, was $52 \%$. This number rose to 90 $\%$ in 2019 and it was reported that the usage rate among women alone was 91\% (21). In Turkey, the internet usage rate of women was only $12.1 \%$ in 2014 but increased to $65.5 \%$ in 2018 (22). A study conducted with pregnant women in 2018 reported that $98.5 \%$ had been using the internet for between $6-10$ years and $1.5 \%$ for $0-5$ years (23). The internet usage rate results from the current study are similar to those reported by other studies. When examining the daily amount of time spent online it was determined that $34.4 \%(n=11)$ of those in the experimental group spent 2 hours online daily and that $43.8 \%(n=14)$ spent 3 hours online per day (Table 3$)$.

Osma (2016) reported that $45.9 \%$ spent 0 to 2 hours daily online, $25 \%$ spent 2 to 4 hours, $10.6 \%$ spent 4 to 6 hours and $18.5 \%$ spent more than 6 hours online daily (19). The current study's results showed a higher duration spent online in the experimental group compared to that of the control group, which was an expected result. In general, internet use rates were high, a result consistent with the literature.

When examining the internet usage purposes, it was determined that most of the postpartum women in the experimental group, 93.8\% $(n=30)$, used it for knowledge acquisition, while $87.5 \%(n=28)$ used it for communication. In the control group, all participants $(n=32)$ stated that they used it for information and communication purposes. In the study conducted by Baker and Yang in 2018 with 117 mothers, it was reported that $44 \%$ of the mothers spent time on social media sites or blogs, while the remainder of them used the internet for communication; furthermore, the same study found that $89 \%$ viewed their friends on social media networks as a kind of social support and that the women used the internet both for a source of knowledge and for social support (24). A study involving 134 pregnant women reported that $76.1 \%$ used the internet for "social networks/ shopping /knowledge acquisition", 35.1\% did not think they had sufficient knowledge and $29.9 \%$ used it to retrieve information quickly since they had difficulties in reaching health personnel. ${ }^{23}$ The Household Information Technologies (IT) usage research report of 2017 showed that $28.6 \%$ of women in that year and 31\% of women in 2018 used the internet to acquire knowledge and information from websites of public institutions. ${ }^{22}$ Women in the postpartum period need more information and support, which may be the reason for the high internet usage rates.

During the postpartum period, mothers face many challenges and difficulties in providing care for themselves and their babies and these situations affect the quality of life after delivery. (25). No significant difference between the two groups was observed in their total quality of life scores ( $p=0.073 ; p>0.05)$, but the experimental group did have higher scores (Table 4). For the primipara in the current study's experimental group, who did not have any maternity experience, the increase of the quality of life score with the aid of midwife support via the mobile application, which helped them to adapt to the new conditions 
after birth and to learn the physiological changes that both the mothers and their babies would undergo, was one of the most remarkable results. While in recent years, the aim of medical care in general has been to increase quality of life, these efforts should be even more pronounced in the postpartum period. It is believed that this can be achieved with the help of mobile applications. The father category in the mobile application developed for this study, which included information for the father on how to support the spouse in terms of breastfeeding and communication suggestions, is thought to be one of the reasons behind the higher scores seen in the experimental group, as compared to those in the control group. These results show that maternal and infant health can be positively affected by spouse participation during the postpartum period.

The mobile application was assessed with the WBESS, and the mean score was determined to be $4.35 \pm 0.58$. The fact that the content of the mobile application was prepared by the midwives in an unbiased manner and based on evidence is important for web-base d educational material $(26,27)$.

The sufficiency level of the material used in the current study was evaluated as medium by $12.5 \%(n=4)$, as good by $25.0 \%$ $(n=8)$ and as very good by $62.5 \%(n=32)$ of the participants in the experimental group. In the current study, the quality of life score of the postpartum women that used the mobile application developed by midwives was higher compared to the women that did not use it. Moreover, the very good sufficiency score that the women from the experimental group ascribed to the WBESS showed that the application positively affected the postpartum period and that the postpartum women were generally satisfied with the application.

In 2017, the mobile application "Health care beyond pregnancy", created to increase the participation rate of postpartum visits, showed that the participation rate of postpartum women who were using the application and their compliance increased (28). Again, in 2017, a systematic review titled "The Role of Mobile Health Applications", carried out to develop the field of prenatal and postnatal care in low and middle-income countries, emphasized that mobile applications, which is one form of mobile health, can improve pregnancy and postpartum care services (29-30). In a study conducted in Ghana, where midwives used a mobile application called mClinic, the midwives reported that the application was useful, easy to use and control and they definitely accepted it as an effective application (10).

A study conducted in Spain examined an application named NaïveBayes, whose aim is the early prediction and detection of postpartum depression. This application provides early intervention in postpartum depression through a simple questionnaire addressing the risk of developing postpartum depression with in the first week. The application can also be used by health professionals who want to monitor patient tests. It has been reported o be easy to use, culturally sensitive and cost-effective (30).

Throughout the world, mobile applications are usedf or different purposes for postpartum women. During the development of the mobile application tested in the current study, all these differences were taken in to consideration and technological features that others did not have were added, along with evidence-based information that was prepared by midwives. It can be said that with these features, the mobile application presented in this study proved to sufficient and successful.

\section{Limitations}

The current study did have several limitations, including primarily, a fairly small sample size of postpartum women, difficulties in data collection and planning, technical errors related to the mobile application, and limited financial opportunities. Other less striking limitations were that certain desired options within the mobile application could not be presented and that some of the postpartum women failed to continue to participate to the end of the study.

\section{CONCLUSIONS}

It was clearly observed that the mobile application support prepared by midwives increased the postpartum quality of life for the women who participated. The Cronbach's alpha coefficient in the current study was 0.970 , which indicated that the scale is highly reliable and can be safely used by adults, in addition to students, for the assessment of material. In light of the study results, which showed that the users were very satisfied with the application, that the educational content was in agreement with expert opinions and that its scope was valid, it is believed that this application could serve as an education model for midwifery applications.

Thus, it is recommended that national and international studies conducted with the aim of supporting postpartum women and midwives focus on supporting midwives/ health professionals in creating timely and evidence-based information that pregnant and postpartum women can safely access via the internet, increasing the digital media literacy of midwives, pregnant women and postpartum women, developing studies and motivational works on this subject, spreading the use of mobile applications in this field and developing suitable equipment.

Funding: This study Kocaeli University

It was financially supported by the Scientific Research Projects (BAP) numbered 2018/059

\section{Authors' Contributions}

$P M$ and $A E$ participated in the study design. PM data collection. $\mathrm{AE}$ and $\mathrm{PM}$ analysis. $\mathrm{AE}$ and $\mathrm{PM}$ reviewed the manuscript.

\section{Acknowledgements}

We would like to thank parents for their participation in this study. 


\section{REFERENCES}

[1] Aslan E. Normal puerperium process and care, (Chapter 14). Nezihe Kızılkaya Beji (Ed) Women's Health and Diseases for Nurses and Midwives, Extended Edition II. Copyright Nobel Publication, Ankara, 2017, 413-472.

[2] Murray S, Mckinney E. Foundations of maternal -newborn and women's health nursing ( $5^{\text {th }}$ Edition). Missouri, 2010, Chapter 17, 391-420.

[3] Şimşek Ç, Esencan T. Nursing care during the postpartum period. Medical Bulletin of Zeynep Kâmil. 2017; 48(4):183-189.

[4] Optimizing postpartum care. ACOG Committee Opinion No. 736. American College of Obstetricians and Gynecologists. Obstet Gynecol. 2018; 131: e140-50.

[5] WHO, Managing Complications In Pregnancy And Childbirth: A Guide For Midwives and Doctors? 2017 (To access: 30.05.2019) https:/ /apps. who. int/iris/bitstream/ handle/ 10665/ 255760/978.924.1565493-eng. pdf; jsessionid= 81926615 AD706AD36BF9A2F8B4787FB1? sequence $=1$

[6] Waegemann CP. MHealth: the next generation of telemedicine?. Telemed J E Health. 2010 Jan-Feb;16(1):23-5. doi: 10.1089/tmj.2010.9990.

[7] Shorey S, Yang YY, Dennis CL. A mobile health app-based postnatal educational program (home-but not alone): descriptive qualitative study. J Med Internet Res. 2018 Apr 19;20(4):e119. doi: 10.2196/jmir.9188.

[8] United Nations Foundations. Mhealth for development: mobile for communication. (To access: 10.04.2019) http:// www. Global problems - global solutions-files. org/ unf website/ assets/publications/technology/mhealth/mHealth_ for_Development_full.pdf

[9] Entsieh AA, Emmelin M, Pettersson KO. Learning the ABCs of pregnancy and newborn care through mobile technology. Glob Health Action. 2015; 8: 29340. 1-10. doi:10.3402/gha.v8.29340.

[10] Vélez O, Okyere PB, Kanter AS, Bakken S. A usability study of a mobile health application for rural Ghanaian midwives. J Midwifery Womens Health. 2014 Mar-Apr; 59(2):184-91. doi: 10.1111/jmwh.12071.

[11] Zadoroznyj M, Brodribb WE, Young K, Kruske S, Miller YD. 'I really needed help': what mothers say about their post-birth care in Queensland, Australia. Women Birth. 2015 Sep;28 (3): 246-51. doi: 10.1016/j.wombi.2015.03.004.

[12] Colaceci S, Giusti A, Chapin EM, Bettinelli ME, De Angelis A, Zambri F, Vellone E, Alvaro R, De Mei B. E-learning to improve healthcare professionals' attitudes and practices on breastfeeding. Breastfeed Med. 2017 Dec;12(10):629-636. doi: 10.1089/bfm.2017.0060.

[13] Kuo MC, Lu YC, Chang P. A Newborn baby care support app and system for mhealth. $11^{\text {th }}$ International Congress on Nursing Informatics, Canada. 2012: p. 228-228

[14] Schulz KF, Altman DG, Moher D; CONSORT group. CONSORT 2010 statement: updated guidelines for reporting parallel group randomised trials. BMJ. 2010 Mar 23; 340:c332. doi: 10.1136/bmj.c332.
[15] Fiş Erümit S. Designing and implementing course material in web based distance education and determining criteria for material designing. Master Thesis. Karadeniz Technical University, Institute of Science and Technology, Trabzon, 2011.

[16] Top ED. Effectiveness of education on reducing of depression symptom level in women during postpartum period. Master Thesis, Adnan Menderes University, Institute of Health Science. Aydın, 2012

[17] Hill PD, Aldag JC, Hekel B, Riner G, Bloomfield P. Maternal postpartum quality of life questionnaire. J Nurs Meas. 2006 Winter;14(3):205-20. doi: 10.1891/jnm-v14i3a005.

[18] Altuntuğ K, Ege E. Validity and reliability of Turkish version of maternal postpartum quality of life questionnaire. Journal of Anatolia Nursing and Health Sciences. 2012; 15(3), 214-222.

[19] Osma J, Barrera AZ, Ramphos E. Are pregnant and postpartum women interested in health-related apps? implications for the prevention of perinatal depression. Cyberpsychol Behav Soc Netw. 2016 Jun;19(6):412-5. doi: 10.1089/cyber.2015.0549.

[20] Peragallo Urrutia R, Berger AA, Ivins AA, Urrutia EG, Beckham AJ, Thorp JM Jr, Nicholson WK. Internet use and access among pregnant women via computer and mobile phone: implications for delivery of perinatal care. JMIR Mhealth Uhealth. 2015;3(1):e25, doi: 10.2196/mhealth.3347.

[21] PEW research, Internet/Broadband Fact Sheet (To access: 22.08.2019), https:// www. pewinternet. org/fact-sheet/ internet-broadband

[22] TUiK, Household Information Technology (IT) Use Survey 2018 Report (To access: 22.08.2019) http://www.tuik.gov.tr/ PreHaberBultenleri.do?id $=27819$

[23] Hadımlı A, Demirelöz Akyüz M and Tuna Oran N. Pregnant women' frequencies and causes of using the internet. Life Sciences (NWSALS). 2018; 13(3):32-43, doi: 10.12739/ NWSA.2018.13.3.4B0018.

[24] Baker B, Yang I. Social media as social support in pregnancy and the postpartum. Sex Reprod Healthc 2018 Oct;17:31-34. doi: 10.1016/j.srhc.2018.05.003.

[25] Bağcı S, Altuntuğ K. Problems experienced by mothers in postpartum period and their associations with quality of life. Journal of Human Sciences. 2016; 13(2): 3266-3279. doi:10.14687/Jhs.V13i2.3884.

[26] Özkan Şat S, Yaman Sözbir Ş. Use of mobile applications and blogs by pregnant women in Turkey and the impact on adaptation to pregnancy. Midwifery. 2018; 62:273-277. doi. org/10.1016/j.midw.2018.04.001.

[27] Guerra-Reyes L, Christie VM, Prabhakar A, Harris AL, Siek KA. Postpartum health information seeking using mobile phones: experiences of low-income mothers. Matern Child Health J. 2016 Nov;20(Suppl 1):13-21. doi: 10.1007/s10995.016.2185-8.

[28] Himes KP, Donovan H, Wang S, Weaver C, Grove JR, Facco FL. Healthy beyond pregnancy, a web-based intervention to improve adherence to postpartum care: randomized controlled feasibility trial. JMIR Hum Factors. 2017 Oct 10;4(4):e26. doi: 10.2196/humanfactors.7964.

[29] Feroz, A., Perveen, S. \& Aftab, W. Role of mhealth applications for improving antenatal and postnatal care in low and middle

How to cite this article: Malli P, Ergin A. The Effect of Mobile Application Support for Postpartum Women on Postpartum Quality of Life. Clin Exp Health Sci 2021; 11: 242-250. DOI: 10.33808/clinexphealthsci.731557 
income countries: a systematic review. BMC Health Services Research 2017, Nov 7. doi: 10.1186/s12913.017.2664-7.

[30] Jiménez-Serrano S, Tortajada S, García-Gómez JM. A mobile health application to predict postpartum depression based on machine learning. Telemed J E Health. 2015 Jul; 21(7):567-74. doi: 10.1089/tmj.2014.0113.

How to cite this article: Malli P, Ergin A. The Effect of Mobile Application Support for Postpartum Women on Postpartum Quality of Life. Clin Exp Health Sci 2021; 11: 242-250. DOI: 10.33808/clinexphealthsci.731557 